\title{
Pensamento e Linguagem: A Língua de Sinais na Resolução de Problemas
}

\section{Language and Thought: The Signals Language in the Problem Solving}

\author{
Maria Helena Fávero* \& Meireluce Leite Pimenta \\ Universidade de Brasília, Brasília, Brasil
}

\begin{abstract}
Resumo
Discute-se a relação pensamento/linguagem e a língua de sinais, num estudo sobre a resolução de problemas matemáticos, do qual participaram surdos entre 18 e 30 anos, alunos de séries iniciais da Educação de Jovens e Adultos de escola pública do Distrito Federal (DF), e desenvolvido em três fases: avaliação das competências matemáticas dos sujeitos sobre a lógica do sistema de numeração e sua notação; pesquisa em LIBRAS para as expressões "n a mais que" e "n a menos que" em situação de comparação de conjuntos; investigação da resolução de problemas matemáticos de comparação em duas situações: a resolução individual sem intervenção e com ela. Os resultados sugerem que a dificuldade dos surdos frente a problemas de matemática advém do processo de escolarização que prima pela aquisição de regras de procedimentos de resolução, em detrimento da aquisição conceitual e pelo uso inadequado da LIBRAS como instrumento para a organização de significados semióticos e aquisição de conhecimentos.

Palavras-chave: Pensamento e linguagem; resolução de problemas; surdez; competências numéricas; língua de sinais.

Abstract

The relationship between thought/language and sign language is discussed in a study about the resolution of mathematical problems, involving deaf subjects aged between 18 and 30, public school students from the initial grades of the Educational Program for Young Adults and Adults in the Distrito Federal (federal capital of Brazil). The study was developed in three phases: evaluation of the subjects' mathematical competencies, regarding the logic of the numerical system and its notation; research about the expressions that best translated "greater than n" and "fewer than n" in LIBRAS (Brazilian Sign Language) in situations where sets were compared; investigation of mathematical problem solving in two different situations: the subject's resolution of the problems with and without intervention. The results suggest that deaf people's difficulties in relation to mathematical problems are connected to the process of schooling due to its emphasis on the acquisition of solving procedures to the detriment of conceptual acquisition. Yet, the misusage of LIBRAS as a tool that favors the organization of semiotic meanings and knowledge acquisition jeopardizing the construction of deaf people's knowledge in this area.

Keywords: Thought and language; problem solving; deafness; numerical competence; sign language
\end{abstract}

Entre as clássicas questões da Psicologia está a relação entre pensamento e linguagem. Para Wundt, a linguagem era o produto de uma comunidade, um fenômeno coletivo tal como a religião, os mitos, a magia. Seguindo a tese de Wundt, Mead defendia que o pensamento era a interiorização da conversação por gestos: "Se o interlocutor utiliza um gesto vocal parecido àquele que ele ouve, e se ele o repete se pondo no lugar daquele que fala, ele possui, então, o significado daquilo que ele ouve, ele tem uma idéia, o significado tornou-se seu" (Mead, 1963, p. 67, 92, citado por Doise, 1982, p. 49). Deste ponto de vista, e defendendo a não dicotomia entre

"Endereço para correspondência: SQN 205, Bloco L, apto. 506, Brasília, DF, 70843-120. Fone: (61)3347 8661. E-mail: faveromh@unb.br

Este trabalho se desenvolveu no âmbito do Projeto Integrado de Pesquisa - "A construção de competências na escola: uma análise psicológica das práticas profissionais e psicopedagógicas no processo educativo" - CNPq, 20012003, coordenado pela primeira autora, e parte dele foi apresentado na dissertação de Mestrado da segunda autora, no Instituto de Psicologia da UnB, para obtenção do título de Mestre em Psicologia. pensamento e linguagem, Mead entendia que a interiorização se realizava de uma maneira privilegiada, quando as condutas verbais se misturavam à conversação por gestos.

Mead é apenas um dos autores aos quais recorre Fávero (2005), para situar a rejeição da dualidade mente-corpo, que, por implicação, fundamenta a rejeição às dicotomias entre pensamento e linguagem e entre indivíduo e sociedade. Como salienta Fávero (2005) o aporte psicosocial herdado dos autores do final do século XIX e início do XX, foi retomado significativamente nas três últimas décadas para ultrapassar as questões dicotômicas e defender a tese segundo a qual entender como se dá a construção do conhecimento envolve muito mais do que saber como se constróem as estratégias cognitivas; envolve também a questão do como e quais são os valores sociais que permeiam as informações, os procedimentos e as próprias atividades (ver, por exemplo, Bruner, 1991; Fávero, 1994; Kintsch \& Greeno, 1985; Vergnaud, 1991). Estava, portanto, retomada, em última análise, a questão da mediação semiótica no desenvolvimento psicológico. 
Do ponto de vista epistemológico, é justamente por meio da compreensão da atividade mediada, que supõe, portanto, um sujeito ativo, que recuperamos o sujeito cognoscente, no sentido de Habermas (1987) isto é, o sujeito que constrói, sem o qual, não haveria sentido, em última análise, nos referirmos a uma Psicologia do Desenvolvimento ou à tese da construção do conhecimento.

Portanto, quando se trata de considerar o sujeito que é surdo, e esta é a tese que temos defendido, a via compatível com o exposto acima, é aquela que se descentra da deficiência neurossensorial auditiva, para se centrar no sujeito e no seu desenvolvimento, o que implica retomar a questão da relação pensamento/linguagem, sob um outro aspecto: aquele que vai além da idéia da oralização do pensamento. Temos hoje respaldo suficiente das pesquisas na área, para entender que o surdo, por meio da língua espaço-visual, se utiliza de sistemas culturais e lingüísticos para construir um sistema de significados, da mesma forma que os ouvintes se utilizando da língua oral auditiva. Ou seja: o consenso entre os pesquisadores é que, embora a língua de sinais seja uma modalidade lingüística diferenciada, uma vez que utiliza o espaço para estabelecer a comunicação, isto não é empecilho para que ela seja considerada, assim como a oral auditiva, um instrumento semiótico, por meio da qual os sujeitos humanos, como diz Bruner (1991) partilham e negociam significados.

Assim, hoje considera-se - embora ainda haja defensores da oralidade, sobretudo no meio escolar - que a língua de sinais é um instrumento adequado para o surdo construir seu conhecimento (Virole, 2000, por exemplo), uma vez que, como assinala Felipe (1997), por meio da língua de sinais é possível a expressão de conteúdos sutis, complexos ou abstratos, de modo que os seus usuários podem discutir qualquer área do conhecimento, da filosofia à política, utilizando-se dos seus recursos, como ocorre com qualquer outra língua, para consolidar a comunicação, isto é, para conferir conteúdo significante aos objetos do mundo e às pessoas que o cercam.

No Brasil, vários pesquisadores defendem esta mesma tese. Góes (1996), por exemplo, entende que a língua de sinais é a língua materna dos surdos, aquela através da qual, outras estruturas se constróem, não havendo, portanto, à priori, limitações cognitivas ou afetivas inerentes à surdez. Para esta autora, o que pode prejudicar o desenvolvimento do surdo é a qualidade das suas experiências e as possibilidades para consolidação da sua linguagem. Em outras palavras, para esta autora, assim como para Ferreira-Brito (1997), os treinamentos auditivos e técnicas de pronúncias de palavras não garantem, necessariamente, a reabilitação da fala, uma vez que parte do conteúdo comunicativo é perdido e a estrutura da linguagem não é preservada, de modo que a interação social entre surdos e ouvintes fica prejudicada.

Vários estudos dão suporte a esta posição. Quadros (1997b), por exemplo, pesquisou a aquisição da linguagem em crianças surdas, filhos de surdos, e constatou que, por ter acesso à uma língua espaço-visual e à sua função lingüística desde o nascimento, estas crianças desenvolvem a linguagem sem deficiências, favorecendo a comunicação.

Portanto, por trás da polêmica entre os que ainda defendem a oralidade para os sujeitos surdos e aqueles que defendem a língua de sinais como língua materna, está a questão da relação entre comunicação e linguagem (ver Acredolo, \& Goodwyn, 2002; Adamson, Bakeman, \& Smith, 2002; Caselli, 2002; Lock, Young, Service, \& Chandler, 2002 e, Masur, 2002). Ou dito em outros termos: se consideramos que a gênese do pensamento está na interação social e se consideramos que a língua de sinais se presta como um veículo de mediação semiótica, então podemos considerá-la como a língua materna dos surdos. Inúmeras pesquisas centradas no desenvolvimento da comunicação humana, desenvolvidas não apenas com surdos, mas também com ouvintes, têm fornecido suporte para a defesa desta tese.

Exemplo disto são os estudos que apontam que, a comunicação gestual pré-lingüística de crianças ouvintes, expostas à língua falada, surge da construção de esquemas sociais que partem das trocas de "olhar", ou do contato do "olho no olho" entre o bebê e a pessoa que cuida diretamente dele. Esses primeiros esquemas sociais progridem para a interação visual, vinculados às referências e a uma posterior manipulação dos objetos. Assim, a criança desenvolve a capacidade de coordenar os gestos indicando suas necessidades, e estabelecendo a comunicação por meio da qual se dão os pequenos ajustes sociais.

Num estudo recente, Adamson et al. (2002) investigaram como a atenção das pessoas em relação aos objetos é estabelecida e como se desenvolve a comunicação referencial de crianças novas. Estes autores demonstraram que os primeiros gestos, assim como as primeiras palavras, são, de fato, vinculadas à ação comunicativa. Para eles, a socialização serve de guia para a aprendizagem de sistemas simbólicos de modo que a coordenação entre a atenção e o gesto, e o desenvolvimento da comunicação referencial, têm por base esta aprendizagem.

Seguindo esta mesma linha de investigação, Lock et al. (2002) analisaram a questão da apontação, evidenciando que, os primeiros gestos do bebê, considerados diretos, como o abrir e fechar a mão para pedir algo que não está ao seu alcance, relaciona-se a uma conseqüência social por meio do qual a criança desenvolve esquemas de comunicação. Assim, a apontação é estimulada pelo contexto no qual a criança está inserida. A contribuição do estudo de Caselli (2002), vai ainda além: acrescenta que não só a apontação faz parte da construção de esquemas de comunicação, mas o "gugunar", o sorrir, o chorar, o balbuciar, entre outras manifestações da criança, também são sinalizadores para que a comunicação seja estabelecida, de modo que os gestos são apoiados no contexto da interação familiar sendo vinculados à ação, às mímicas e às repetições da função do objeto. Esta autora chama também a atenção para o fato de que, não somente as crianças utilizam-se de gestos no início da sua construção verbal, como os adultos utilizam os gestos como suporte para a comunicação oral, o que é compatível com a referência que fizemos no início, à George Mead. 
Em resumo, hoje sabemos que os gestos fazem parte do desenvolvimento da linguagem, e que eles, aos poucos, cedem lugar para a palavra, no caso dos ouvintes, ou para os sinais, no caso dos surdos, mas não desaparecem por completo em ambas as modalidades sendo que, os gestos na língua de sinais são menos perceptíveis do que nas línguas orais, pois compartilham do mesmo espaço visual onde a comunicação é estabelecida, enquanto os gestos na língua oral são mais perceptíveis pois dão suporte à comunicação oral.

Portanto, as pesquisas nos ensinam que a criança pequena, seja surda ou não, nos primórdios da aquisição da linguagem, utiliza os gestos para expressar suas necessidades e para estabelecer vínculos sociais. Assim, as experiências lingüísticas da criança surda, exposta à língua de sinais desde o seu nascimento e processadas, portanto, na modalidade espaço-visual, podem ser comparadas à aquisição das línguas orais. De fato, inúmeras pesquisas evidenciam que, o contexto lingüístico no qual a criança surda está inserida, influencia diretamente sua aquisição da linguagem, do mesmo modo como ocorre com a criança ouvinte (ver, por exemplo, Bellugi, O'Grady, \& LilloMartin, 2002; Boyes Braem, 2002; Erting, Prezioso, \& O'Gragy Hynes, 2002; Pettito, 2002; Pizzuto, 2002 e Reilly, McIntire, \& Bellugi, 2002). Mais especificamente, Erting et al. (2002), defendem que, a criança surda quando exposta à língua de sinais desde o seu nascimento, participa de uma "cultura visual" como um primeiro meio de comunicação, que eles denominam de viso-gestual. Esta interação favorece a atenção da criança para as atividades que ocorrem em seu campo visual, e para os sinais utilizados na interação mãe-bebê, o que favorece, por sua vez, uma interação mais ativa com o ambiente, além de estabelecer a socialização com base na linguagem viso-gestual, por meio de um processo de construção de esquemas comunicativos (Caselli, 2002).

No que diz respeito à aquisição do conteúdo semântico, Goldim-Meadow e Morford (2002) concluíram, após um estudo comparativo sobre a aquisição da língua de sinais por crianças ouvintes e crianças surdas, ambas filhos de pais surdos, que esta aquisição depende do contexto lingüístico no qual as crianças estão inseridas, sendo que a criança surda desenvolve uma maior combinação e complexidade gestual, se comparada às crianças ouvintes. Bellugi et al. (2002) ressaltam que esta complexidade pode estar relacionada a fatores que dizem respeito à percepção espacial. Assim, sublinham Goldim-Meadow e Morford (2002), as mãos, para os surdos, assumem a função de instrumento comunicativo, de modo que a criança que não pode falar, cria espontaneamente, por meio das mãos, um sistema gestual com marcação visoespacial.

Portanto, podemos concluir com os autores citados, que existe uma mudança qualitativa das ações que a criança desempenha no decorrer do processo de aquisição lingüística: a criança surda, exposta à linguagem viso-espacial desde o seu nascimento, tem maiores progressos na aprendizagem inicial da linguagem do que a criança ouvinte, quando exposta à linguagem oral. Por isto mesmo, estes autores vão além e defendem que a linguagem viso-espacial é mais acessível à criança do que a linguagem oral, seja ela surda ou não.

Portanto, podemos dizer que os processos de aquisição da linguagem, seguem uma ordem para todas as crianças: crianças surdas e crianças ouvintes utilizam gestos diretos no primeiro período desta aquisição, gestos estes que, em períodos posteriores, cedem lugar aos gestos refe-renciais, aos sinais no caso dos surdos e às palavras (orais), no caso dos ouvintes. Os gestos referenciais podem ser chamados de signos e são estruturados para representar os referentes e, portanto, construídos em um processo de interação. Assim, os gestos, os sinais e as palavras formam esquemas complexos, tanto para os surdos como para os ouvintes, sustentados a partir das interações estabelecidas.

Para Virole (2000), estes referentes, tanto espaciais como os temporais são, na língua de sinais, marcados, em geral, por meio de uma linha imaginária ou virtual em diferentes localizações em relação ao corpo. O posicionamento dos sinais no espaço é significante para expressar simbolicamente inúmeros conhecimentos. De um modo geral, os sinais são formados pela combinação de movimentos, formato e posicionamento que as mãos tomam no "espaço." Estas articulações, segundo Felipe (1997), podem ser comparadas aos fonemas e às vezes aos morfemas da língua oral, sendo chamadas, nas línguas de sinais, de parâmetros, de modo que as combinações destes parâmetros, ou unidades mínimas distintivas, como denomina Ferreira-Brito (1997), formam e estruturam os sinais, sinais estes, que obedecem a classes lexicais que representam as categorias gramaticais da LIBRAS - Língua Brasileira de Sinais - como os verbos, adjetivos, advérbios e pronomes. Os classificadores, também importantes, descrevem e representam classes de objetos por meio das similaridades, de espessura, de tamanho ou de forma, tendo funções descritivas ou de substituição, com o objetivo de evidenciar a forma. Estes classificadores, para Ferreira-Brito (1997), são categorias de objetos que se reagrupam de acordo com a forma, podendo ser considerados como: (a) parte de um tipo de morfema gramatical que é afixado a um morfema lexical; (b) sinal para mencionar a classe a que pertence o referente desse sinal, para descrevê-lo quanto à forma e tamanho, ou para descrever a maneira como esse referente é estabelecido ou se comporta na ação verbal.

Segundo essa autora, o classificador é uma forma gramatical que existe em número restrito dentro de uma língua e estabelece al gum tipo de concordância, e na LIBRAS, os classificadores tomam as configurações das mãos que, relacionadas às coisa, pessoas, situações, funcionam como marcadores de concordância. São formas que, substituindo o nome que as precedem, podem vir junto ao verbo para classificar o sujeito ou o objeto que está ligado à ação do verbo.

Portanto, contrário ao clássico argumento à favor da oralidade para os surdos, segundo o qual a língua de si- 
nais seria pobre pela sua iconicidade, hoje temos pesquisadores que defendem, não apenas que a língua viso-espacial é essencial para o desenvolvimento cognitivo dos surdos, como afirmam que a criança surda apresenta vantagens em relação à memória, à atenção e aos esquemas espaciais, se comparada com crianças ouvintes da mesma idade (ver, por exemplo, Reilly, McIntire, \& Bellugi, 2002). Além disto, Virole (2000) defende que, os surdos que utilizam a língua de sinais reagem rapidamente a estímulos visuais direcionados ao campo periférico, possuindo melhor desenvolvimento potencial da região occipital, evidenciando a ativação das áreas primárias visuais, quanto à detenção dos movimentos, principalmente em se tratando do campo visual direito.

Em resumo - e isto fundamentou nosso estudo - podemos afirmar que, o uso do espaço na língua de sinais, funciona como discurso sintático, onde os níveis lingüísticos como nome, pronome referencial, referência espacial, léxico, significado, parâmetros da língua (ponto de articulação, movimento, posição das mãos, orientação e direção), são coordenados e estruturados.

No entanto, parece que tais informações ainda são pouco divulgadas de um modo geral, tanto no contexto social mais amplo, como no contexto escolar, de modo que a corrente oralista influenciou e ainda influencia a forma de se perceber o surdo, uma vez que esta não se reduz somente à defesa do treinamento da fala, ou a uma reeducação do campo residual auditivo; sua defesa interfere na prática social, na perspectiva pedagógica e na representação sobre a capacidade cognitiva dos surdos (ver Skliar, 1998). Como se sabe, o oralismo contribuiu, não somente para o enfraquecimento das associações dos surdos, mas também para dificultar o acesso dos surdos a atividades intelectuais e ao mercado de trabalho, como aponta a pesquisa de Quadros (1997a): 74\% dos surdos não chegam a concluir o ensino fundamental.

Portanto, não é de se surpreender que, no discurso escolar haja uma séria contradição: afirma-se, ao mesmo tempo, de um lado, que os surdos têm dificuldades nas atividades intelectuais, mas, que ele tem mais facilidade para a aprendizagem da matemática do que para a aprendizagem do português e, de outro lado, se afirma que o surdo tem muita dificuldade para resolver problemas de matemática (Fávero \& Pimenta, 2002).

No presente artigo relatamos um estudo no qual, para enfrentar o desafio de desvendar esta contradição, se assumiu a proposta de Fávero (2002), que defende uma descentração do modelo médico focado na deficiência neurossensorial auditiva para centrar-se no sujeito surdo, propondo uma mudança radical segundo dois eixos: (a) desenvolver pesquisas centradas nas peculiaridades do desenvolvimento do surdo; (b) desenvolver pesquisas centradas na aquisição de conceitos matemáticos, tendo por método de investigação o próprio procedimento de intervenção psicopedagógica, o que significa considerar a atividade mediada.

\section{Método}

Nosso estudo foi estruturado em três fases. Na primeira procedemos a uma avaliação das competências numéricas dos sujeitos surdos, na segunda, pesquisamos os termos em língua de sinais para comparação de conjuntos e na terceira, propusemos aos sujeitos surdos, uma situação de resolução de problemas escritos. Cada fase foi desenvolvida com surdos adultos, alunos de uma escola Pública do DF, situada no Plano Piloto de Brasília entre o $1^{\circ}$ e o $2^{\circ}$ semestre de 2002. Estes alunos surdos são submetidos às mesmas normas do Ensino Supletivo, devendo cumprir uma jornada diária de 4 horas de aula, das 19:00 horas às 23:00 horas, com um máximo de $25 \%$ de faltas.

O fato de haver um rodízio muito grande entre eles, tornou-se inviável a participação dos mesmos sujeitos em todas as fases, de modo que os descrevemos à cada fase. Do mesmo modo, uma vez que os resultados obtidos em cada uma das fases, fundamentou a seguinte, optamos por apresentar o procedimento de cada uma delas, seguido dos resultados e discussão, para então, elaborarmos uma conclusão final.

$\mathrm{Na} 1^{\mathrm{a}}$ fase, 3 sujeitos surdos do sexo masculino, alunos do $1^{\circ}$ segmento da Educação de Jovens e Adultos (EJA) na modalidade supletivo, foram submetidos à avaliação das competências numéricas por meio de uma adaptação da Prova Conceitual de Resolução de Problemas NuméricosECPN (Groupe CIMETE, 1999). Trata-se de um instrumento por meio do qual, utilizando-se de pequenas quantidades de objetos concretos (fichas, botões, etc.) e sem o recurso à escrita, verifica-se o desempenho dos sujeitos, em diferentes contextos numéricos: situações de descrição e comparação, igualdade, quantificação da relação de ordem e pesquisas de estado iniciais ou de transformação.

Dois dos sujeitos eram portadores de disacusia neurossensorial severa à direita, sendo um com disacusia neurossensorial profunda à esquerda (19 anos de idade), que será identificado de $\mathrm{D}$ e o outro com disacusia neurossensorial profunda à direita (23 anos de idade), que será identificado de W. O terceiro, era portador de disacusia neurossensorial bilateral profunda (25 anos), e será identificado de agora em diante de F. Juntando os períodos em escolas do ensino regular e aqueles em escola para surdos, cada um deles tinham freqüentado a escola no mínimo por 8 anos.

A aplicação da referida prova foi individual e registrada em vídeo. Por meio da sua transcrição criamos, para cada sujeito, tabelas de 3 colunas, onde na primeira se descreve a tarefa proposta, na segunda o desempenho do sujeito em cada tarefa e sua interação com a experimentadora (identificada por E) e na terceira, a análise deste desempenho. À título de exemplo, apresentamos um extrato da Tabela 1, elaborada com os dados obtidos junto a F. 
Fávero, M.H., \& Pimenta, M. (2006). Pensamento e Linguagem: A Língua de Sinais na Resolução de Problemas.

Tabela 1

Extrato da Análise da Avaliação do Sujeito F na Prova EPCN

$\begin{array}{lll}\text { Tarefas } & \text { Desempenho do sujeito Análise do desempenho }\end{array}$

$\begin{array}{ll}1^{\circ} \text { Descrever a situação } & \text { E: "O que eu fiz?" } \\ \text { "O que podemos dizer des- } & \text { R: "Deu comida bichos." } \\ \text { sa situação?" } & \text { E: "Quem recebeu mais?" } \\ \text { Situação inicial: } & \text { R: "Leão." } \\ \text { Sapo s: } 2 & \text { E: "Por quê?" } \\ \text { Rato r: } 3 & \text { R: "Comeu 7." }\end{array}$

Leão L: 7

\begin{abstract}
O sujeito percebe a quantidade de cada elemento sem a necessidade de apontação. Apenas observa a distribuição e exprime corretamente a palavra número da coleção. Reconhece a distribuição feita pela E. Conta cada elemento do conjunto associando o cardinal à coleção. Conta de 1 em 1 e anuncia o número da coleção.
\end{abstract}

$\begin{array}{ll}2^{\circ} \text { Comparar } & \text { F olha para as coleções e si- } \\ \text { "Quem tem mais?" } & \text { naliza: "Esse tem mais porque } \\ \text { "Como você sabe?" } & \text { come mais, mais gordo. Esse, } \\ \text { Situação Inicial: } & \text { come pouco (aponta para o } \\ \text { Sapo: } 2 & \text { rato) esse come normal, sim- } \\ \text { Rato: } 3 & \text { ples e o sapo come menos } \\ \text { Leão: } 7 & \text { porque é mais magro." }\end{array}$

O sujeito cria uma situação e parece ficar preso a ela. O sujeito não demonstrou dificuldade em perceber a quantidade de elementos dos conjuntos, contando silenciosamente cada um. Reconhece quem tem mais e quem tem menos com comentário não numéricos.
Os resultados evidenciaram que os sujeitos apresentavam os conceitos de adição e de subtração associados à idéia de unir ou separar conjuntos e a compreensão da igualdade relacionada à correspondência termo à termo, além de associar operações à situações, mesmo quando estas não estavam claramente conectadas. Nas tarefas que envolviam a transformação por soma na descoberta de estado inicial ou final, os sujeitos demonstraram compreender as relações entre os números, utilizando as duplas de contagem para frente e para trás, controladas com a seqüência de palavras-número.

No entanto, nas tarefas que envolviam a comparação do tipo "n a mais" com estados iniciais idênticos e diferentes, os sujeitos apresentaram dificuldades em diferenciar as relações estáticas e as medidas estáticas. Ou seja, embora os sujeitos compreendessem a medida estática e a relação entre elas, não compreendiam, de imediato, a situação de comparação em si, de modo que, mesmo tendo as ferramentas matemáticas, não percebiam como utilizá-las nas tarefas propostas.

O sujeito $\mathrm{F}$ apresentou dificuldade na compreensão da tarefa de comparação de conjuntos quando E utilizou em LIBRAS a expressão "a mais". O primeiro procedimento de $\mathrm{F}$ foi igualar os conjuntos (31, 3r, 3s) e acrescentar 1 elemento ao conjunto referência, fazendo com que este ficasse com 4 elementos. O sujeito, portanto entendia a questão " $n$ a mais" como a quantidade final de elementos do conjunto de referência.

Como o próprio sujeito igualou, os conjuntos, E, então, passou a perguntar em LIBRAS: "está igual? Está diferente?" Então, depois de aproximadamente quatro tentativas, F, separou 4 elementos do conjunto reserva, mas não acrescentou em nenhum dos três conjuntos iniciais. Ou seja, ele não adicionou, como pedia a tarefa. Ele só chegou à solução adequada da tarefa quando E solicitou-lhe que adicionasse os 4 elementos que havia separado do conjunto de referência. Nos itens seguintes, E adotou a mesma seqüência de interação com $\mathrm{F}$ e o sujeito resolveu adequadamente as questões, e em menos tempo.

Assim, o procedimento adotado por este sujeito, de igualar os conjuntos, antes de adicionar o "n a mais", foi adotado por E, na interação com os sujeitos D e W, ou seja: comparar, igualar e acrescentar o " $n$ a mais". Este mesmo procedimento foi relatado por Nunes e Bryant (1997) em seus estudos com crianças ouvintes, como estratégia pedagógica para facilitar a compreensão das relações entre as medidas estáticas e medidas de transformação, e nos estudos de Selva e Brandão (2000), também com crianças ouvintes, como um procedimento espontâneo de resolução frente a problemas de comparação. Estes últimos relatam que as crianças ouvintes tendem a igualar os conjuntos para somente então desenvolver a questão do "quantos a mais." Serrano-Pau (1995), encontrou resultados semelhantes, trabalhando com crianças surdas. Esta autora relata que as crianças surdas tendem a compreender a expressão " $n$ a mais" como uma operação de soma.

Diante disto, concluiu-se que existem dois modos de ver a mesma questão: a eqüalização em problemas de comparação como estratégia pedagógica e como estratégia cognitiva. Se considerarmos que F, por ele mesmo, igualou primeiramente os conjuntos para depois resolver a questão " $n$ a mais," podemos supor que as ações de equalizar problemas de comparação, deve-se a uma questão de estratégia cognitiva, que pode, por sua vez, ser a base das estratégias pedagógicas, como adotado por E, com os sujeitos D e W.

Além disto, levantamos a hipótese de que a dificuldade apresentada pelos sujeitos F, D e W, no entendimento da tarefa de comparação de conjuntos, com a expressão " $n$ a mais", podia estar vinculada a uma questão de negociação de significados, em LIBRAS, de modo que, levantamos a 
hipótese de que os sinais utilizados pela experimentadora no momento da tarefa talvez não tivessem correspondido aos conceitos expressos na situação de comparação.

Por isso mesmo, desenvolvemos a $2^{\text {a }}$ fase do nosso estudo, com o intuito de sistematizar uma situação, por meio da qual fosse possível pesquisar, em língua de sinais, o que melhor traduzisse as expressões " $n$ a mais" $\mathrm{e}$ " $n$ a menos" em situação de comparação de conjuntos.

Desta $2^{\text {a }}$ fase, que denominamos de Prova Adicional de Comparação de Conjuntos (PACC), participaram além de D, mais 4 outros sujeitos surdos: MC, do sexo masculino, 33 anos, portador de disacusia neurossensorial severa à direita e disacusia neurossensorial profunda à esquerda; $\mathrm{A}$, portadora de disacusia neurossensorial bilateral profunda, do sexo feminino, 22 anos; JS, portadora de disacusia neurossensorial bilateral profunda, do sexo feminino, 32 anos e PS, professor surdo, de 34 anos, oralizado, concursado pela Secretaria do Estado de Educação do DF, professor de LIBRAS para crianças surdas, portador de disacusia neurossensorial bilateral profunda.

A PACC consistia na distribuição de conjuntos desiguais de bombons, de tal forma que o número de elementos de um conjunto não correspondesse ao número de elementos do outro, e a diferença entre eles fosse sempre de um elemento. A partir desta situação, por meio da LIBRAS eram colocadas as questões: Está igual? Está diferente? O que tem diferente? Por que diferente? Quanto diferente? Quem mais? Quem menos? Quantos esse mais? Quantos esse menos? Falta quanto? Sobra quanto? Em seguida a experimentadora distribuía os bombons de tal forma que a diferença entre os conjuntos fosse maior que um elemento. Diante desta nova situação a experimentadora pedia para que o sujeito comparasse os conjuntos por meio das perguntas da situação anterior, igualasse os conjuntos e acrescentasse " $n$ a mais" ou retirasse " $n$ a menos" do conjunto referência.

No decorrer destas tarefas foram avaliadas: a contagem, os procedimentos de distribuição de bombons, os comentários a respeito da diferença entre os conjuntos e a capacidade de conceituar a situação de comparação que envolvia a expressão " $n$ a mais" e " $n$ a menos". A PACC foi desenvolvida em três momentos: (a) primeiro com o professor surdo (PS); (b) depois com o sujeito D; (c) depois com os sujeitos JS, MC e A, em situação de interação. Nestes dois últimos momentos foram utilizados os termos específicos em LIBRAS como sugeridos por PS.

No primeiro momento, PS, assim como os sujeitos da primeira fase já descrita, entende a expressão "a mais" como a quantidade final de elementos de um dos conjuntos. Após a repetição da questão, PS iguala os conjuntos e acrescenta um elemento e pergunta se é esta a questão. Diante da resposta positiva, PS esclarece que, a estrutura utilizada por $\mathrm{E}$ - “... de tal forma que um fique com um bombom a mais do que o outro" - nas suas palavras "não combina com o surdo", isto é, que a estrutura utilizada por E, dificulta a compreensão, por não se tratar da LIBRAS. Segundo PS, ao comparar os conjuntos, E deve evidenciar qual conjunto tem mais elementos e qual tem menos, por meio da posição das mãos no espaço: a mão que representa o conjunto maior deve ficar mais a cima da mão que representa o conjunto menor e a mão que representa o conjunto menor deve subir até a altura da que está mais acima, mostrando a igualdade entre os conjuntos. Em seguida, deve ser usado o sinal de "mais" acompanhado do número sinalizado. Portanto, PS sugere que as estratégias adotadas em situação de comparação devem seguir alguns passos: comparar e igualar a quantidade de elementos dos conjuntos e adicionar elementos ao conjunto de referência. Tal sugestão refere-se, em última análise, ao que já foi dito sobre os classificadores em LIBRAS, na nossa introdução.

Portanto, concluiu-se que, para a apresentação destas tarefas aos surdos, quatro passos deveriam ser seguidos:

1. Quantificar os conjuntos.

2. Representar "qual o conjunto tem mais elementos e qual o conjunto tem menos elementos" por meio da posição que as mãos ocupam no espaço.

3. Igualar os conjuntos.

4. Adicionar o " $n$ a mais." Em resumo, esta primeira etapa da $2^{\text {a }}$ fase do nosso estudo nos deu os seguintes dados: os termos mais adequados em LIBRAS, são aqueles que indicam a similaridade e a diferença entre os conjuntos: "Está igual? Está diferente? Por que diferente? O que é diferente? Quanto diferente?"; a expressão facial em LIBRAS é fundamental e por meio dela, podemos utilizar dois outros termos que traduzem as expressões " $n$ a mais" e "n a menos": falta quanto? Sobra quanto? Portanto, PS nos indicou certas estratégias que, respeitando a estrutura da LIBRAS, deveriam favorecer a compreensão da situação problema.

Do ponto de vista psicológico, podemos dizer que tais estratégias maximizam a experiência do sujeito com as diferentes funções do número, isto é, como medida estática, como medida de transformação e como relações estáticas, e que não se trata, portanto, de uma estratégia trivial, e vai de encontro com o que Vergnaud (1991) sugeriu para ouvintes, ou seja, o conceito de número envolve sua compreensão como medida, como relação e como transformação, considerando que, tal conceito e as competências associadas a ele, formam uma rede complexa parcialmente ordenada e constituída de uma parte estável e de avanços instáveis, estando intimamente relacionado às situações, às operações e às relações que o próprio conceito suscita. Dito em outros termos, a construção do conceito de número resulta do conjunto das situações práticas e de problemas teóricos que lhe dão sentido, das propriedades que o sujeito descobre ou aprende nestas situações e das representações simbólicas que permitem suscitar a representação dos números, as relações e as operações. Dito em outros termos, as estratégias sugeridas por PS tendo por base a LIBRAS, podem favorecer a aprendizagem dos surdos, uma vez que dão sentido às propriedades do número.

No segundo e terceiro momentos desta fase, aprofundamos a pesquisa dos termos de comparação quantitativa em LIBRAS, acrescentando à $P A C C$, outras tarefas, criadas na própria situação de interação entre a experimentadora e os sujeitos, a partir da dificuldade destes e levando 
Fávero, M.H., \& Pimenta, M. (2006). Pensamento e Linguagem: A Língua de Sinais na Resolução de Problemas.

em conta os procedimentos já referidos acima. Esta era, na verdade, a única forma de colocar à prova as sugestões de PS. E, efetivamente os resultados obtidos confirmaram a sua pertinência: o desempenho dos sujeitos evidenciou que as estratégias de resolução frente a problemas de comparação seguem uma seqüência particular: comparar, igualar e retirar ou acrescentar " $n$ " elementos ao conjunto.

Vale lembrar que, a literatura especializada aponta que os problemas de comparação do tipo que utilizamos são, efetivamente, complexos, tanto para os surdos quanto para os ouvintes (ver, por exemplo, Carpenter, \& Moser, 1983; Hiebert, Carpenter, \& Moser, 1982; Kintsch, \& Greeno, 1985; Serrano-Pau, 1995; Vergnaud, 1991), de modo que a sua dificuldade não pode ser justificada nem pela limitação biológica do sujeito que é surdo, nem por uma suposta limitação lingüística. Tanto é que a $1^{\mathrm{a}}$ parte desta fase, isto é, aquela realizada junto ao professor surdo, evidenciou que a limitação do surdo frente a problemas de comparação envolvendo a relação " $n$ a mais" e " $n$ a menos" pode estar relacionada ao modo como este conceito é mediado em LIBRAS.

Portanto, podemos desde já adiantar uma das conclusões deste estudo. Para uma prática psico-pedagógica que pretenda favorecer o desenvolvimento psicológico do surdo três aspectos são fundamentais: (a) o professor (ou outro profissional) que lida com surdos deve ter fluência em LIBRAS; (b) as estratégias de ensino de matemática devem favorecer experiências significativas para o aluno; (c) o aluno deve ter, no seu processo de escolarização, a oportunidade de lidar com as diferentes funções do número.

Foi com base nestas considerações que desenvolvemos a $3^{\mathrm{a}}$ e úl tima fase deste estudo, centrada, no que era desde o início, nosso norte: a resolução de problemas matemáticos textuais, do tipo utilizado na escola, envolvendo a comparação de conjuntos na relação " $n$ a mais" e " $n$ a menos." Dela participaram seis sujeitos: o sujeito D, o sujeito A, o sujeito W e o sujeito MC, já mencionados e mais dois: ML, de 24 anos, sexo masculino, portador de disacusia neurossensorial severa à direita e disacusia neurossensorial profunda à esquerda e $\mathrm{H}$, de 29 anos, sexo masculino, portador de disacusia neurossensorial bilateral profunda.

Foram utilizados seis problemas, inspirados na literatura sobre resolução de problemas em matemática (Carpenter
\& Moser, 1983; Kintsch \& Greeno, 1985): dois de diferença desconhecida, dois de qualidade desconhecida e dois de referência desconhecida.

Os problemas foram apresentados em três sessões diferentes, de dois em dois, conforme a ordem de apresentação acima, perfazendo um total aproximado de 6 horas, registradas em vídeo. Os problemas foram entregues à cada sujeito do grupo, digitados em folha de papel sulfite. Em cada uma das três sessões, seguiu-se o mesmo procedimento: primeiro era solicitado que os problemas fossem resolvidos individualmente; em seguida, a experimentadora solicitava aos sujeitos que lessem os problemas em língua de sinais; depois a experimentadora auxiliava a compreensão dos sujeitos, utilizando-se da LIBRAS, caracterizando-se assim, uma intervenção psicopedagógica centrada na comparação de conjuntos, principalmente no que se refere à diferenciação do número como medida estática e do número como relação estática.

Apresentamos as soluções de cada sujeito, para cada problema, nas Tabelas 2, 3, 4, 5, 6 e 7. Os sujeitos foram identificados na coluna vertical à esquerda e as soluções dos problemas à direita, na horizontal, obedecendo a seqüência registrada individualmente, pelos sujeitos.

Como podemos ver, na Tabela 2 e 3 , as tentativas dos sujeitos, na situação individual de solução dos problemas, parecem se caracterizar como tentativas de ensaio e erro. Invariavelmente, todos trabalham com os numerais que aparecem no enunciado e na seqüência em que aparecem. Apenas um dos sujeitos, W, apresenta em primeiro lugar, uma adição, que pode se relacionar com a expressão "a mais" que aparece no texto do problema. Tirando o fato dos sujeitos demonstrarem saber da existência de diferentes operações, ("é de mais?" "é de menos?"), e de usarem a notação da soma, da subtração e da multiplicação, podemos ver que eles não resolvem os problemas, nem aquele com " $n$ a mais" nem aquele com " $n$ a menos". Mesmo que a $1^{\mathrm{a}}$ resposta de ML, por exemplo, apareça como uma solução correta $(8-5=3)$, não podemos dizer que foi uma solução consciente, uma vez que no segundo problema (a mais que) ele dá a mesma solução em $1^{\circ}$ lugar e repete as outras soluções, alterando apenas a ordem dos numerais.

Tabela 2

Soluções Individuais de Resolução de Problemas de Comparação com a Expressão "n a mais"

$1^{\circ}$ Problema escrito: Maurício tem 8 reais. Douglas tem 5 reais. Quantos reais Maurício tem a mais que Douglas? (Situação de comparação com diferença desconhecida).

$\begin{array}{ll}\text { Sujeitos } & \text { Soluções individuais sem intervenção } \\ \mathrm{W} & \left.\left.\left.1^{\circ}\right) 8+5=13 \text { reais; } 2^{\circ}\right) 8-5=3\left(3 \text { quanto reais ?); } 3^{\circ}\right) 3-5=2 ; 4^{\circ}\right) 8 \times 5=40 \\ \text { ML } & \left.\left.\left.1^{\circ}\right) 8-5=3 ; 2^{\circ}\right) 5 \times 8=40 ; 3^{\circ}\right) 8+5=13 \\ \text { MC } & \left.1^{\circ}\right) 8 \text {, OO reais } \times 5 \text {, OO reais }=40 \text { reais. } \\ \text { A } & \left.\left.\left.1^{\circ}\right) 8 \text { reais }+5 \text { reais }=13 \text { reais; } 2^{\circ}\right) 8 \text { reais }-5 \text { reais }=3 \text { reais; } 3^{\circ}\right) 8 \times 5=40 \\ \text { H } & \left.1^{\circ}\right) 8 \times 5=40 \text { reais } \\ \text { D } & \left.1^{\circ}\right) 8 \times 5=40 \text { reais. Resposta: Quantos reais Maurício tem a mais que Douglas } 40 \text { reais }\end{array}$


Tabela 3

Soluções Individuais de Resolução de Problemas de Comparação com a Expressão "n a menos"

$2^{\circ}$ Problema escrito - Maurício tem 8 reais. Douglas tem 5 reais. Quantos reais Douglas tem a menos que

Maurício? (Situação de comparação com diferença desconhecida):

$$
\begin{array}{ll}
\text { Sujeitos } & \text { Soluções individuais sem intervenção } \\
\text { W } & \left.\left.\left.\left.1^{\circ}\right) 8 \times 5=40 ; 2^{\circ}\right) 5 \times 40=20,5 ; 3^{\circ}\right) 20,5 \times 5=11,05 ; 4^{\circ}\right) 8-5=3 ; \text { e) } 11,05 \times 5=56,05 . \\
\text { ML } & \left.\left.\left.1^{\circ}\right) 8-5=3 ; 2^{\circ}\right) 8 \times 5=40 ; 3^{\circ}\right) 5+8=13 . \\
\text { MC } & \left.1^{\circ}\right) 8,00 \text { reais }+5,00 \text { reais }=13,00 \text { reais. } \\
\text { A } & \left.\left.1^{\circ}\right) 8-5=3 ; 2^{\circ}\right) 8 \times 5=24 . \\
\text { H } & \left.\left.\left.1^{\circ}\right) 8+5=13 ; 2^{\circ}\right) 5-5=0 ; 3^{\circ}\right) 8-5=3 . \\
\text { D } & \left.1^{\circ}\right) 8+5=13 \text { reais. Quantos reais Maurício tem a menos que Maurício? } 13 \text { reais. }
\end{array}
$$

Comparando as duas tabelas, podemos ver que há um certo padrão de respostas para cada sujeito, havendo algumas particularidades: MC, faz uso da vírgula seguida de dois zeros e a palavra reais para multiplicar 8 por 5 , porém as vírgulas desaparecem na resposta (40 reais). W, na tabela 2 , propõe em sua terceira soluções: $3-5=2$, e por fim multiplica 8 x 5 e, na tabela 3 , na segunda, terceira e quinta solução, multiplica números decimais, que não constam no problema $(20,2 ; 11,05)$, sendo que não multiplica corretamente; $H$ apresenta uma solução na segunda tentativa repetindo o segundo numeral do problema (5 $5=0)$.

No geral, estes dados evidenciam que os nossos sujeitos ainda não traduzem em suas notações, a representação da situação proposta pelo problema, tentando solucioná-la por meio de operações aritméticas desvinculadas da questão proposta, o que pode explicar o registro de mais de uma solução para uma mesma questão. Tal procedimento, não se distancia daqueles apresentados pelos sujeitos adultos e ouvintes, no estudo de Fávero e Soares (2002), que também não demonstraram saber estabelecer relações entre a notação das operações e uma situação problema. Para estas autoras os referidos adultos não só apresentavam dificuldades no reconhecimento da notação convencional, como também tinham dificuldade em perceber esta notação como forma de registrar situações que podem ser quantificadas. Ou seja, os nossos dados evidenciaram que a produção dos nossos sujeitos, do ponto de vista do uso de diferentes sinais para a notação, não é pobre; o que é pobre é a relação entre o uso destes e seu significado, atrelado a uma situação particular.

A intervenção de E, em um primeiro momento, se baseia na diferenciação das medidas estáticas por meio da comparação de conjuntos, e em um segundo momento pela identificação da relação estática: "Quantos mais?” Diante disto, os sujeitos D, A e W, rapidamente anunciam a solução adequada do problema. ML além de chegar à solução favorável, após a intervenção de E, propõe uma equalização entre as medidas estáticas por meio de uma marcação espacial dos números sinalizados: "este espaço entre o 8 e o 5 ,... é 3, é 3.” A estratégia utilizada por ML evidencia que o número como uma relação estática pode ser mais facil- mente compreendido se a subtração estiver ligada à idéia de transformação.

Em nenhum momento $\mathrm{E}$ fornece a resposta para aos sujeitos, mas os induz a confrontar suas respostas. Importante notar que o sujeito $\mathrm{W}$ após um intervalo sem se manifestar, traduz, podemos dizer assim, o problema que era baseado em uma comparação de medidas estáticas, em um problema envolvendo duas medidas estáticas e uma medida de transformação, ou seja, o sujeito subtrai de uma medida estática a medida de transformação, chegando à resposta correta: "Maurício tem 8, ele empresta 5 para Douglas, ele fica com 3”. Depois desta intervenção de W, MC sugere igualar os conjuntos subtraindo três elementos do conjunto que inicialmente tinha 8 , controlando esta subtração por meio de dupla de contagem para trás, ou seja MC, verbaliza seu procedimento, subtraindo um elemento de cada vez, chegando ao resultado 5, que representa a igualdade entre as duas medidas estáticas iniciais. Além disto MC utiliza o termo “sempre” em LIBRAS que indica a permanência ou a continuidade de algo para se referir à medida estática. Diante disto, podemos assumir que a LIBRAS foi o instrumento pelo qual a comunicação pôde ser estabelecida com os nossos sujeitos, que são surdos, e pelo qual podemos efetivar a intervenção.

As Tabelas 4 e 5 sugerem uma mudança qualitativa dos registros referentes às tentativas de solução individual frente aos problemas propostos. A notação das operações obedece às regras de cálculo em ambas as tabelas. Não existe incidência de erros nem nas notações nem nos cálculos aritméticos. Na Tabela 4, vemos, no entanto, que apenas 2 dos 6 sujeitos desta sessão, traduzem em sua notação, a situação problema. Os sujeitos, não utilizam, desta vez, os numerais que aparecem no enunciado vinculado ao termo "a mais", ou seja, os sujeitos trabalham com os numerais utilizando os recursos aritméticos que dispõe para operar com as quantidades referidas. Podemos pensar que a intervenção da sessão anterior tenha influenciado o desempenho dos sujeitos.

Os sujeitos também elaboraram representações dos problemas por meio do desenho, como os exemplos abaixo, que reproduzimos nos utilizando dos recursos do computador. 
Fávero, M.H., \& Pimenta, M. (2006). Pensamento e Linguagem: A Língua de Sinais na Resolução de Problemas. forma:

D desenha 2 conjuntos de 3 elementos cada, da seguinte Maurício

\section{in iो}

3
3

$+3$

6
Douglas

in in

3
MC desenha da seguinte forma:

Maurício i

Douglas $\quad$ i

A desenha 3 elementos representando a quantia de Maurício e 6 representando a quantia de Douglas:

\section{Maurício $\rightarrow \dot{\mathbb{N}} \dot{\mathbb{N}}$}

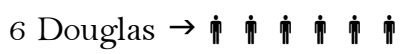

Tabela 4

Soluções Individuais de Resolução de Problemas de Comparação com a Expressão "n a mais"

$3^{\circ}$ Problema escrito: Maurício tem 3 reais. Douglas tem 3 reais a mais do que Maurício. Quantos reais Douglas tem? (Situação de comparação com qualidade desconhecida).

$\begin{array}{ll}\text { Sujeitos } & \text { Soluções sem intervenção } \\ \mathrm{W} & \left.1^{\circ}\right) 3-3=0 \\ \mathrm{ML} & \left.\left.\left.\left.1^{\circ}\right) 3-3=0 ; 2^{\circ}\right) 3 \times 3=9 ; 3^{\circ}\right) 3+3=6 ; 4^{\circ}\right) 9: 3=3 \\ \mathrm{MC} & \left.1^{\circ}\right) 3+3=6 . \\ \mathrm{A} & \left.1^{\circ}\right) 3-3=0 \\ \mathrm{H} & \left.1^{\circ}\right) 3 \times 3=9 \\ \mathrm{D} & \left.1^{\circ}\right) 3+3=6\end{array}$

Tabela 5

Soluções Individuais de Resolução de Problemas de Comparação com a Expressão " $n$ a menos"

$4^{\circ}$ Problema escrito: Maurício tem 8 reais. Douglas tem 5 reais a menos que Maurício. Quantos reais Douglas tem? (Situação de comparação com qualidade desconhecida).

\begin{tabular}{ll}
\hline Sujeitos & Soluções individuais sem intervenção \\
W & $\left.1^{\circ}\right) 8-5=3$ \\
ML & $\left.1^{\circ}\right) 8-5=3$ \\
MC & $\left.1^{\circ}\right) 8-5=3$ \\
A & $\left.1^{\circ}\right) 8-5=3$ \\
H & $\left.1^{\circ}\right) 8-5=3$ \\
D & $\left.1^{\circ}\right) 8-5=3$ \\
\hline
\end{tabular}

De um modo geral, os sujeitos igualam as coleções para estabelecer a relação: quantos a mais, ou, quantos a menos e o termo "sempre" aparece novamente associado à diferenciação de medidas estáticas. A utilização deste termo, porém, pode ser questionada, pois no mesmo instante em que se parece com uma estratégia cognitiva apoiada nos recursos da própria língua de sinais, ela pode ser a tradução de mais uma regra aprendida na escola para a resolução desta situação particular.
Podemos pensar ainda que, o confronto de soluções proporcionado pelas interações, tanto na primeira sessão, quanto na segunda sessão, favoreceu o monitoramento cognitivo, permitindo que os sujeitos atuassem não somente sobre suas próprias atividades cognitivas e metacognitivas, mas também sobre as ações dos outros e conseqüentemente sobre as atividades cognitivas e metacognitivas deles. Ou seja, ao mesmo tempo em que o sujeito sofre influência, também influencia. Para Fávero e Soares (2002) esta es- 
tratégia ajuda o sujeito a perceber o significado de suas respostas e mais ainda, a compreender as relações entre as operações, suas notações e a situação problema apresentada. Diante dos nossos dados e seguindo o raciocínio destas autoras podemos dizer que a estratégia de confrontar as respostas dos sujeitos, por meio de questionamentos, favoreceu a resolução de problemas matemáticos, o que não é novidade em se tratando de sujeitos em processo de escolarização. Podemos dizer que a novidade é concluir que a LIBRAS é um rico instrumento semiótico para isto.

Nas Tabelas 6 e 7, vemos que os sujeitos procuraram registrar, por meio de notações, uma única solução para cada problema apresentado, com exceção de MC e ML.

Tabela 6

Soluções Individuais de Resolução de Problemas de Comparação com a Expressão "n a mais"

$5^{\circ}$ Problema escrito: Maurício tem 8 reais. Ele tem 5 reais a mais do que Douglas. Quantos reais Douglas tem?

(Situação de comparação com referência desconhecida).

$\begin{array}{ll}\text { Sujeitos } & \text { Soluções individuais sem intervenção } \\ \text { W } & \text { Ausente } \\ \text { ML } & \left.\left.\left.\left.1^{\circ}\right) 8-5=3 ; 2^{\circ}\right) 8+5=13 ; 3^{\circ}\right) 8 \times 5=40 ; 4^{\circ}\right) 5: 8=8 \text { e sobra } 1 \\ \text { MC } & \left.\left.\left.1^{\circ}\right) 8 \times 5=40 ; 2^{\circ}\right) 8+5=13 ; 3^{\circ}\right) 8-5=3 \\ \text { A } & \left.1^{\circ}\right) 8-5=3 ; \\ \text { H } & \left.1^{\circ}\right) 8+5=13 \\ \text { D } & \left.1^{\circ}\right) 8-3=5\end{array}$

Tabela 7

Soluções Individuais de Resolução de Problemas de Comparação com a Expressão "n a menos"

$6^{\circ}$ Problema escrito: Maurício tem 3 reais. Ele tem 5 reais a menos que Douglas. Quantos reais Douglas tem?

(Situação de comparação com referência desconhecida).

\begin{tabular}{ll}
\hline Sujeitos & Soluções individuais sem intervenção \\
W & Ausente \\
ML & $\left.\left.\left.1^{\circ}\right) 5-3=2 ; 2^{\circ}\right) 5+3=8 ; 3^{\circ}\right) 5 \times 3=15$ \\
MC & $\left.1^{\circ}\right) 5-3=2$ \\
A & $\left.1^{\circ}\right) 3-5=2$ \\
H & $\left.1^{\circ}\right) 3-5=2$ \\
D & $\left.1^{\circ}\right) 3+5=8$ \\
\hline
\end{tabular}

De um modo geral, os sujeitos seguem um mesmo padrão para a resolução dos problemas: utilizam os números que aparecem no enunciado e na seqüência em que aparecem, associando a eles os sinais convencionais da operação aritmética. Ou seja: os sujeitos novamente não traduzem em suas notações a questão proposta pelo problema.

Podemos ver ainda que, se comparados aos resultados das Tabelas 4 e 5, os nossos sujeitos, nas Tabelas 6 e 7 , apresentam um número maior de respostas incorretas, o que pode ser explicado pela complexidade do problema proposto, o que, por sua vez indica a sua dificuldade no que diz respeito à aquisição da lógica do sistema numérico.

Por meio da transcrição das interações na situação de intervenção, evidencia-se que a medida estática desconhecida é mais facilmente compreendida quando a subtração está ligada a uma idéia de transformação. Além disto, evidencia-se que os sujeitos entendem esta subtração como uma estratégia de igualar os conjuntos e, portanto, uma ação direta sobre os dados do problema, como questiona MC: "Eu peço emprestado para ele? Emprestado, 5, 5? Penso 3."

No $6^{\circ}$ problema, $\mathrm{D}$ e $\mathrm{H}$, chegam à solução correta, em um primeiro momento, tão logo se dá a leitura do problema por meio da LIBRAS. No entanto, A começa a ler o problema, mas não estabelece a conexão entre o pronome "ele" e o seu referente, o que sugere dificuldade no domínio de signos lingüísticos.

\section{Conclusão}

Como se sabe, na resolução de problemas matemáticos a compreensão da situação vai além do domínio das palavras e das operações aritméticas. Isso implica em desmistificar a afirmação de que o surdo tem dificuldade em resolução de problemas textuais devido à dificuldade do domínio do português. 
Fávero, M.H., \& Pimenta, M. (2006). Pensamento e Linguagem: A Língua de Sinais na Resolução de Problemas.

$\mathrm{Na}$ verdade, qualquer que seja o aluno, surdo, ouvinte, criança, adulto, em processo alfabetização ou não, terá que lidar com a questão da leitura funcional e com a questão da lógica do sistema numérico e de medidas. Concluímos ainda que não é somente a estrutura sintática e textual do problema que interfere na compreensão do mesmo, mas uma questão muito mais grave: a forma como a escola media o conhecimento matemático acrescido da falta de proficiência em LIBRAS do professor que lida com o surdo.

Nosso estudo nos permite defender que o ensino da matemática na educação de surdos, deve propiciar a contextualização dos fatos numéricos, permitindo a negociação dos significados matemáticos de modo a favorecer a construção de conceitos, como defendido por Fávero e Soares (2002). Sabemos que esta negociação e a construção semiótica só se tornam possíveis por meio dos recursos da linguagem. No caso dos surdos, pudemos ver que a LIBRAS é o veículo mais indicado para esta mediação, propiciando a lida com as propriedades e as diferentes funções que o número pode assumir: como medida, como relação e como transformação.

Portanto, podemos concluir que a qualidade da mediação semiótica na escolarização dos surdos traz implicações diretas sobre a sua aquisição do conhecimento e sobre seu próprio desenvolvimento. Por isso mesmo, reafirmamos a defesa do uso da LIBRAS como instrumento de mediação semiótica no contexto psicopedagógico.

\section{Referências}

Acredolo, L. P., \& Goodwyn, S. W. (2002). Sing language among hearing infants: The spontaneous development of symbolic gestures. In V. Volterra \& C. J. Erting (Eds.), From Gesture to language in hearing and deaf children (pp. 68-78). Washington, DC: Gallaudet University Press

Adamson, L. B., Bakeman, R., \& Smith, C. B. (2002). Gesture, words, and early objects sharing. In V. Volterra C. J. Erting (Eds.), From Gesture to language in hearing and deaf children (pp. 31-41). Washington, DC: Gallaudet University Press.

Bellugi, U., O’Grady, L., \& Lillo-Martin, D. (2002). Enhancement of spatial cognition in Deaf Children. In V. Volterra \& C. J. Erting (Eds.), From Gesture to language in hearing and deaf children (pp. 278-298). Washington, DC: Gallaudet University Press.

Boyes Braem, P. (2002). Acquisition of handshape in american sing language: A preliminary analysis. In V. Volterra \& C. J. Erting (Eds.), From Gesture to language in hearing and deaf children (pp. 107-127). Washington, DC: Gallaudet University Press.

Bruner, J. (1991). The proper study of man. In J. Bruner (Ed.), Acts of meaning (pp. 1-32). Cambridge, MA: Harvard University Press.

Carpenter, T. P., \& Moser, J. M. (1983). Acquisition of mathematics concepts and processes. New York: Academic Press.

Caselli, M. C. (2002). Communicative gesture and first words. In V. Volterra \& C. J. Erting (Eds.), From Gesture to language in hearing and deaf children (pp. 56-67). Washington, DC: Gallaudet University Press.

Doise, W. (1982) L' explication en psychologie sociale. Paris: PUF.
Erting, C. J., Prezioso, C., \& O'Gragy Hynes, M. (2002). The interactional context of deaf mother-infant communication. In V. Volterra \& C. J. Erting (Eds.), From Gesture to language in hearing and deaf children (pp. 97-106). Washington, DC: Gallaudet University Press.

Fávero, M. H. (1994). O valor sócio-cultural dos objetos e a natureza sócio-cultural das ações humanas: A mediação exercida pelo meio escolar no desenvolvimento e na construção do conhecimento. In Anais do XVII International School Psychology Colloquium e II Congresso de Psicologia Escolar (pp. 58-61). Campinas, SP: Átomo.

Fávero, M. H. (2002). A aquisição da matemática em condições especiais e a intervenção psicopedagógica. In Anais do I Congresso Brasileiro de Psicologia (pp.73-83). São Paulo, SP.

Fávero, M. H. (2005). Desenvolvimento psicológico, mediação semiótica e representações sociais: Por uma articulação teórica e metodológica. Psicologia Teoria e Pesquisa, 21(1), 17-25.

Fávero, M. H., \& Pimenta, M. L. (2002). A aquisição de conceitos matemáticos pelos surdos: Análise e reflexões. In Anais do I Congresso Internacional do INES-Surdez e Pós-Modernidade: Novos rumos para a educação brasileira (pp. 135-138). Rio de Janeiro, RJ: INES.

Fávero, M. H., \& Soares, M. T. C. (2002). Iniciação escolar e notação numérica: Uma questão para o estudo do desenvolvimento adulto. Psicologia Teoria e Pesquisa, 18(1), 43-50.

Felipe, T. A. (1997). Introdução à gramática da LIBRAS. Série Atualidades Pedagógicas, 4(3), 81-107.

Ferreira-Brito, L. (1997). Língua Brasileira de Sinais - LIBRAS Série Atualidades Pedagógicas, 4(3), 19-61.

Góes, M. C. R. (1996). Linguagem, surdez e Educação. Campinas, SP: Autores Associados.

Goldim-Meadow, S., \& Morford, M. (2002). Gesture in early child language. In V. Volterra \& C. J. Erting (Eds.), From Gesture to language in hearing and deaf children (pp. 249-262). Washington, DC: Gallaudet University Press.

Groupe CIMETE. (1995). Compétences et incompétences en arithmétique. Une aide au diagnostic et à l'action pédagogique particulièrement destinée aux enfants affectés de difficultés sévères d'apprentissage. ANAE/ Approche Neuropsychologique des Apprentissages chez l'Enfant, hors série, 58-63.

Habermas, J. (1987). Conhecimento e interesse (J. N. Heck, Trad.) Rio de Janeiro, RJ: Guanabara.

Hiebert, J., Carpenter, T. P., \& Moser, J. M. (1982). Cognitive development and children's solution to verbal arithmetic problems. Journal for research in mathematics education, 13(2), 83-98.

Kintsch, W., \& Greeno, J. G. (1985). Understanding and solving word arithmetic problems. Psychological Review, 12(1), 109129

Lock, A., Young, A., Service, V., \& Chandler, P. (2002). Some observations on the origins of the pointing gesture. In V. Volterra \& C. J. Erting (Eds.), From Gesture to language in hearing and deaf children (pp. 42-55). Washington, DC: Gallaudet University Press.

Masur, E. F. (2002). Gestural development, dual-directional signaling, and the transition to words. In V. Volterra \& C. J. Erting (Eds.), From Gesture to language in hearing and deaf children (pp. 18-30). Washington, DC: Gallaudet University Press.

Nunes, T., \& Bryant. P. (1997). Crianças fazendo matemática. Porto Alegre, RS: Artes Médicas.

Pettito, L. A. (2002). The transition from gesture to symbol. In V. Volterra \& C. J. Erting (Eds.), From Gesture to language in hearing and deaf children (pp. 153-162). Washington, DC: Gallaudet University Press. 
Pizzuto, E. (2002). The early development of deixis in american sign language: What is the point? In V. Volterra \& C. J. Erting (Eds.), From Gesture to language in hearing and deaf children (pp. 142-152). Washington, DC: Gallaudet University Press. Quadros, R. M. (1997a). Educação de surdos: A aquisição da linguagem. Por to Alegre, RS: Artes Médicas.

Quadros, R. M. (1997b). Aquisição da linguagem por crianças surdas. LIBRAS. Série Atualidades Pedagógicas, 4(3), 81-107.

Reilly, J, S., McIntire, M. L., \& Bellugi, U. (2002). Faces: The relationship between language and affect. In V. Volterra \& C. J. Erting (Eds.), From Gesture to language in hearing and deaf children (pp. 128-141). Washington, DC: Gallaudet University Press.

Selva, A. M. V., \& Brandão, A. C. P. (2000). A notação da escrita na resolução de problemas por crianças pré-escolares. Psicologia: Teoria e Pesquisa, 16(3), 45-52.

Serrano-Pau, C. (1995). The deaf child and solving problems of arithmetic: The importance of comprehensive reading. American-Annals-of-the-Deaf, 140(3), 287-290.

Skliar, C. (1998). Bilingüismo e biculturalismo. Uma análise sobre as narrativas tradicionais na educação de surdos. Revista Brasileira de Educação, 8, 44-56.

Vergnaud, G. (1991). El niño, las matemáticas y la realidad. México: Trillas.

Virole, B. (2000). La pensée visualle. In B. Virole (Ed.) Psychologie de la surdité (Deuxième édition, pp. 201-218). Paris: De Boeck \& Lacier. 